\title{
The maximal activity of phosphate-dependent glutaminase and glutamine metabolism in the colon and the small intestine of streptozotocin-diabetic rats
}

\author{
M.S.M.Ardawi \\ Department of Clinical Biochemistry, College of Medicine and Allied Sciences, King Abdulaziz University, Jeddah, Saudi Arabia
}

\begin{abstract}
Summary. The effects of short- and long-term diabetes on the maximal activities of phosphate-dependent glutaminase and glutamine metabolism were studied in the colon and the small intestine of streptozotocin-diabetic rats. The maximal activity of colonic phosphate-dependent glutaminase was decreased [ $44 \%$ in mucosal scrapings $(p<0.01) ; 29 \%$ in whole colon $(p<0.001)$ ] or unchanged in short- or long-term diabetes respectively. That of the small intestine was increased in both short- $(110 \%)$ and long-term $(200 \%-500 \%)$ diabetes; insulin treatment corrected this increase. Acute insulin-deficiency (using anti-insulin serum) resulted in the increase $(18 \%, p<$ 0.05 ) of the activity of only intestinal glutaminase. Chemically-induced acidosis and alkalosis decreased $(46 \%, p<0.001)$ and increased $(24 \%, p<0.001)$, respectively, the activity of in-
\end{abstract}

testinal glutaminase, but had no effect on the colonic enzyme. Changes in glutaminase of the enlarged colon and small intestine were only detectable when activities were measured in whole organ. Arteriovenous-difference measurements showed diminished metabolism of plasma glutamine by the gut which correlated with the duration of the state of diabetes, and was accompanied by enhanced release by skeletal muscle and increased uptake by both kidney and liver. It is concluded that insulin is directly or indirectly involved in the regulation of glutamine metabolism of the gut.

Key words: Glutaminase, metabolism, glutamine, diabetes, colon, small intestine.

response to starvation [12], thermal injury [13] and experimental diabetes [8]. In addition, the activity of glutaminase of colonic mucosa was found to decrease in response to starvation [6]. This study was designed to determine if adaptive changes in glutaminase activity of the colon occurs in response to diabetes as compared to that of the small intestine, and whether they are due to the associated acidosis or other aspects of the state of diabetes. The relevance of such changes to the regulation of glutamine metabolism during the onset of chronic or acute states of experimental diabetes induced by streptozotocin or anti-insulin serum, respectively, was investigated. Moreover, in an attempt to provide an explanation for the diminished rates of glutamine removal by the gut during diabetes, arteriovenous-difference measurements across tissues known to utilize (kidney and liver) or release (skeletal muscle) glutamine were made in diabetic rats.

\section{Materials and methods}

\section{Animals}

Male Wistar albino rats (200-280 g) or guinea pigs (250-350 g) were obtained from King Fahd Medical Research Center (KFMRC), Jed- the regulation of glutamine utilization [11]. The activity of intestinal glutaminase has been reported to change in 
Table 1. Body weight, colon and small intenstine weights, plasma glucose and plasma insulin in control and streptozotocin-diabetic rats

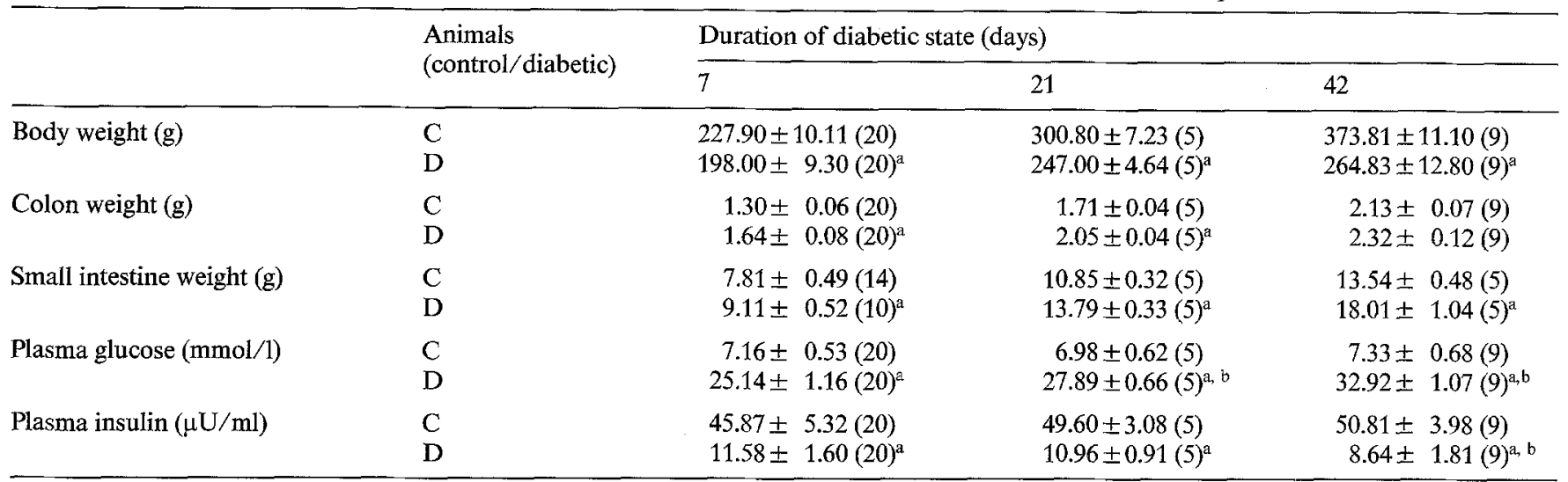

Values are presented as means \pm SD with number of rats given in parentheses. Diabetic rats $(D)$ are streptozotocin-induced diabetic animals, and controls (C) are age-matched control rats. Significant differences from control rats are indicated by ${ }^{a}(p<0.001)$. Significant differences from 7 -day-diabetic rats are indicated by ${ }^{\mathrm{b}}(p<0.05)$

dah, Saudi Arabia. Animals were maintained on a standard laboratory diet [commercial rat cubes containing $(\mathrm{w} / \mathrm{w})$ approximately $18 \%$ protein, $3 \%$ fat, $77 \%$ carbohydrate and $2 \%$ organic-salt mixture with a vitamin supplement] (Grain Silos and Flour Mills Organization, Jeddah, Saudi Arabia) and water ad libitum. Rats were made diabetic by a single intravenous injection of streptozotocin $(70 \mathrm{mg} / \mathrm{kg}$ body weight in $50 \mathrm{mmol} / \mathrm{l}$-sodium citrate, $\mathrm{pH} 4.5$ ) under light ether anaesthesia. Rats showing blood glucose greater than $20 \mathrm{mmol} / 1$ were used at 721 and 42 days after induction of diabetes (see Table 1). In some experiments, diabetic rats received three intraperitoneal injections of insulin at $8 \mathrm{~h}$ intervals at doses which maintained blood glucose concentrations and rates of body-weight gain comparable to those in control animals. The daily food intakes of normal and streptozotocin-diabetic rats were recorded.

Acute insulin deficiency was induced in normal rats under ether anaesthesia by the injection of $1.2 \mathrm{ml}$ of anti-insulin serum into the femoral vein. Rats were allowed to recover from anaesthesia and killed at 60 min after induction of the acute insulin deficiency. The volume of anti-insulin serum used was sufficient to produce elevation in the plasma glucose concentrations $(25.32 \pm 2.57 \mathrm{mmol} / 1, n=5)$ after $60 \mathrm{~min}$. Control rats received $1.2 \mathrm{ml}$ of saline $(0.9 \% \mathrm{NaCl})$. In experiments designed to reverse the effects of anti-insulin serum, animals that had been injected with anti-insulin serum for $10 \mathrm{~min}$ were further injected with bovine insulin either at a dose equivalent to the titre of the antiserum or at a dose of 5.5 units/rat in excess over the titre before killing.

Antiserum to bovine insulin was raised in guinea pigs as described previously [14]. The neutralizing capacity of the collected antiserum was about 3.6 units of bovine insulin $/ \mathrm{ml}$ or 3.8 units of rat insulin $/ \mathrm{ml}$ as determined by immunochemical titration.

Chronic metabolic acidosis and alkalosis were induced by replacement of drinking water with $[1.5 \%(\mathrm{w} / \mathrm{v})]$ solutions of $\mathrm{NH}_{4} \mathrm{Cl}$ and $\mathrm{NaHCO}_{3}$ respectively.

\section{Chemicals and enzymes}

All chemicals and enzymes were obtained from Boehringer Corp, London, UK, except for the following: L-glutamine and glycine were obtained from Sigma Chemical Co., Poole, Dorset, UK; all inorganic reagents were obtained from Fisons, Loughborough, Leicester, UK. Streptozotocin was obtained from BDH Chemicals, Poole, Dorset, UK.

\section{Preparation and incubation of colonocytes and enterocytes}

Colonocytes were prepared as previously described by Ardawi and Newsholme [6]. Enterocytes were prepared as described by Watford et al [5]. Incubations of either isolated colonocytes or enterocytes were performed at $37^{\circ} \mathrm{C}$ in $25 \mathrm{ml}$ plastic flasks as described previously [6]. Incubations were terminated by adding $200 \mu \mathrm{l}$ of $\mathrm{HClO}_{4}(25 \% \mathrm{w} / \mathrm{v})$ to the incubation flask and cooling the mixture to $0^{\circ} \mathrm{C}$. Precipitated protein was removed by centrifugation at $13500 \mathrm{~g}$ for $2 \mathrm{~min}$, the supernatant neutralized with $\mathrm{KOH}(20 \% \mathrm{w} / \mathrm{v})$ containing $500 \mathrm{mmol} / 1$-triethanolamine, and the $\mathrm{KClO}_{4}$ removed by centrifugation at $13500 \mathrm{~g}$ for $3 \mathrm{~min}$.

\section{Preparation of homogenates and assay of glutaminase activity}

Animals were killed by cervical dislocation. The small intestine (from the duodenum to the caecum) or the colon (from the caecum to the rectal ampulla) was rapidly removed, washed by forcing ice-cold $0.9 \%$ $\mathrm{NaCl}$ through the lumen and then cut longitudinally. Intestinal or colonic mucosa were separated from the underlying muscle by scraping with a microscope slide, weighed and homogenized in 5 vol of extraction medium [16] by using a Polytron homogenizer (PCU-2, at position 3) for $10-20 \mathrm{~s}$ at $0^{\circ} \mathrm{C}$. In some experiments, the whole of the small intestine or the whole of the colon (mucosa plus underlying muscle layers) was extracted as described above. Glutaminase activity in intestinal or colonic homogenates was determined by the method of Curthoys and Lowry [17]. Mucosal preparations were treated immediately before assay with $[0.05 \% \mathrm{v} / \mathrm{v}]$ Triton-X-100.

\section{Arteriovenous-difference measurements}

Rats were anaesthetized with ether and blood withdrawn from venous vessels. Samples were taken into heparinized syringes from renal femoral, hepatic-portal and hepatic veins, and from the abdominal aorta. Samples $(0.5-1.0 \mathrm{ml})$ were quickly added to $1.0 \mathrm{ml}$ ice-cold $\mathrm{HClO}_{4}$ $(10 \% \mathrm{v} / \mathrm{v})$. Precipitated protein was removed by centrifugation at $13500 \mathrm{~g}$ for $5 \mathrm{~min}$, the supernatant neutralized with $\mathrm{KOH}(20 \% \mathrm{w} / \mathrm{v})$ containing $500 \mathrm{mmol} / \mathrm{l}$-triethanolamine, the $\mathrm{KClO}_{4}$ removed by centrifugation at $13500 \mathrm{~g}$ for $3 \mathrm{~min}$ and then used for metabolite determination. Arteriovenous differences were calculated for hindlimb (aorta-femoral vein), kidney (aorta-renal vein), gut (aorta-portal vein) and liver [ $(3 / 4$ portal vein $+1 / 4$ aorta)-hepatic vein] respectively.

\section{Determination of metabolites and plasma insulin}

Metabolites in neutralized extracts of cells plus medium were determined spectrophotometrically (with a Beckman DU-6 recording spectrophotometer) by standard enzymeic methods: D-glucose [18]; Lglutamine and ammonia [1]; L-glutamate [19]; L-Alanine [20]; and 
Table 2. Effects of various experimental conditions on the maximal activity of glutaminase of the colon and the small intestine in control and streptozotocin-diabetic rats

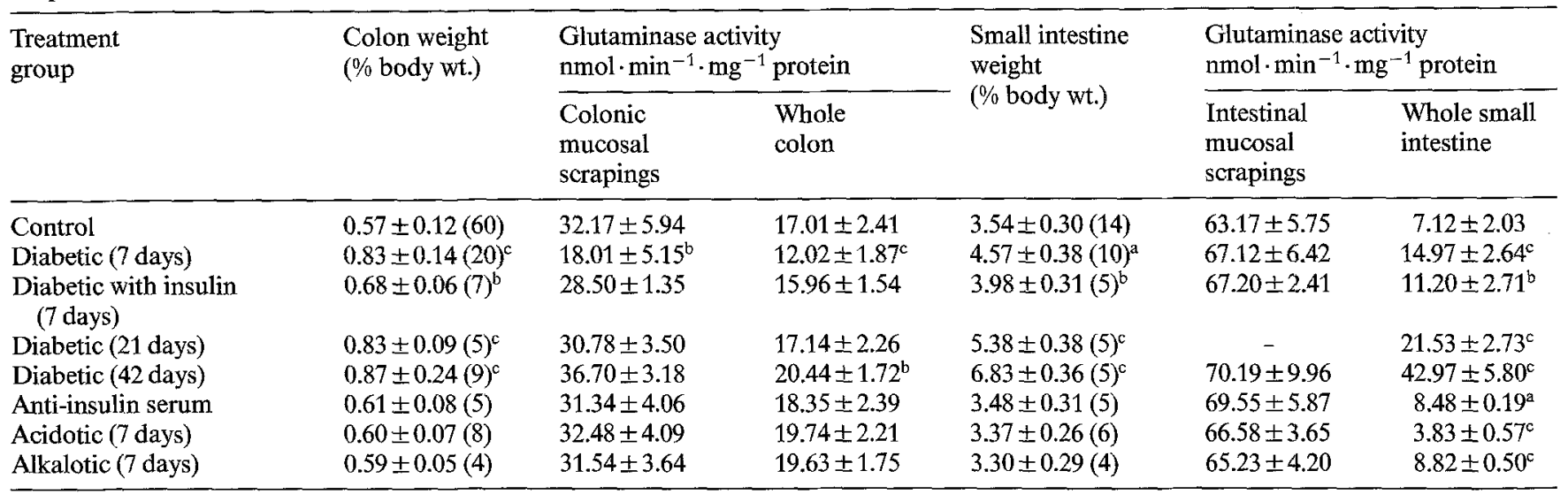

Rats were treated as described in the Materials and methods section. Values are presented as means \pm SD with number of rats given in parentheses. Significant differences from control rats are indicated by ${ }^{\mathrm{a}}(p<0.05) ;{ }^{\mathrm{b}}(p<0.01) ;{ }^{\mathrm{c}}(p<0.001)$

L-Aspartate [21]. Protein was determined by the procedure of Lowry et al. [22]. Plasma insulin was measured by radioimmunoassay technique (Diagnostic Products Corp., Los Angeles, Calif., USA)

\section{Expression of results}

Glutaminase activity is expressed as nmol of glutamate formed $/ \mathrm{min}$ per mg of protein at $37^{\circ} \mathrm{C}$. Changes in concentrations of substrate or metabolites during the incubation of isolated cells were determined from the net change between zero time and 20 min incubation. Rates of substrate utilization or metabolite production are expressed as $\mu \mathrm{mol} / \mathrm{min}$ per $\mathrm{g}$ dry weight of cells. To determine the dry weight of colonocytes or enterocytes, prepared cell suspensions were pipetted into a preweighed glass tube; after centrifugation at $500 \mathrm{~g}$ for $10 \mathrm{~min}$, the supernatant medium was carefully aspirated and the remaining pellet dried at $70^{\circ} \mathrm{C}$ to constant weight.

\section{Statistical analysis}

The data are expressed as mean $\pm \mathrm{SD}$, and comparisons between sets of data were made using the Student's t-test.

\section{Results}

The body weight gain of streptozotocin-induced diabetic rats was markedly less than that of age-matched controls (Table 1). The plasma levels of glucose in diabetic animals were significantly higher than that found in corresponding controls $(p<0.001)$. Plasma glucose levels in rats with diabetes of 42-day duration were significantly higher than those in rats with diabetes of 7-day duration $(p<0.05)$. Plasma insulin levels in diabetic rats were markedly lower than those of control rats (Table 1). Diabetes resulted in an increase in the weight of both the colon and the small intestine (Table 1); however, the percentage increase in the size of the colon decreased with increasing duration of the diabetic state. This is indicated by the constant colon-weight-bodyweight ratio $(46 \%)$ during short or prolonged periods of diabetes. These observations contrast with those found for the small intestine (Table 2). Both the colon and the small intestine of diabetic rats exhibited increased yields of mucosal scrapings.

\section{Glutaminase activity}

The maximal activities of glutaminase in rat colonic mucosa (measured in scrapings or whole of the colon) are presented in Table 2. A marked decrease in the activity of glutaminase was observed in short-term (7 days) diabetes, being $46 \%$ or $30 \%$ when measured in colonic scrapings or whole of the colon respectively. The decrease in colonic glutaminase activity could be completely reversed by the administration of insulin in vivo (Table 2). These observations contrast with those found for glutaminase activity in the small intestine, which was increased in response to short- or long-term diabetes when measured in the whole organ only (Table 2).

Although the diminished activity of glutaminase in colonic mucosal preparations of short-term diabetic rats was similar to that observed in starved animals [6], it was not the consequence of semi-starvation which is known to be associated with the induction of diabetes by streptozotocin $[4,23]$. Hence, whereas food intake was significantly decreased on the first two days after streptozotocin injection $(p<0.001)$, the intake had returned to normal by the third day (Table 3 ).

Acute insulin deficiency (using anti-insulin serum) resulted in no apparent change in the activity of glutaminase of the colon, but a slight increase (18\%) was evident in that of the small intestine (Table 2). The effect of anti-insulin serum on intestinal glutaminase activity was rapidly reversed by insulin [being 7.24士 $0.36(n=5), \mathrm{nmol} \cdot \mathrm{min}^{-1} \cdot \mathrm{mg}^{-1}$, in the whole small intestine]. Unlike the activity of the intestinal glutaminase, colonic enzyme was not affected by long-term changes in the state of acid-base balance whether measured in either scrapings or the whole colon (Table 2). 
Table 3. Daily food intake of control and streptozotocin-diabetic rats

\begin{tabular}{|c|c|c|c|c|c|c|}
\hline Treatment group & Day & \multicolumn{5}{|c|}{ Food intake (g/day) } \\
\hline Control $(n=8)$ & & $37.39 \pm 5.16$ & $36.48 \pm 3.51$ & $36.54 \pm 4.41$ & $37.06 \pm 1.63$ & $36.78 \pm 2.80$ \\
\hline
\end{tabular}

Rats were made diabetic ( 7 days) as described in the Materials and methods section, and their daily food intake monitored and recorded against that of control rats. Values are presented as means \pm SD with numbers of rats in parentheses. Significant differences from control rats are indicated by ${ }^{\text {a }}(p<0.001)$

Table 4. Effects of short-term diabetes on glutamine metabolism by isolated colonocytes and enterocytes in control and streptozotocin-diabetic rats

\begin{tabular}{llllll}
\hline $\begin{array}{l}\text { Cellular } \\
\text { preparation }\end{array}$ & $\begin{array}{l}\text { Treatment } \\
\text { group }\end{array}$ & \multicolumn{4}{l}{ Rates of utilization or production $\mu \mathrm{mol} \cdot \mathrm{min}^{-1} \cdot \mathrm{g}^{-1} \mathrm{dry}$ wt } \\
\cline { 2 - 6 } & & Glutamine & Glumamate & Aspartate & Alanine \\
\hline Colonocytes & Control & $-5.82 \pm 0.89(5)$ & $3.53 \pm 0.66$ & $0.85 \pm 0.14$ & $0.66 \pm 0.13$ \\
& Diabetic & $-4.90 \pm 0.18(5)^{\mathrm{a}}$ & $2.83 \pm 0.15^{\mathrm{a}}$ & $0.72 \pm 0.09$ & $0.54 \pm 0.03$ \\
& (7 days) & & & & $3.90 \pm 0.38$ \\
Enterocytes & Control & $-12.18 \pm 1.04(5)$ & $3.53 \pm 0.42$ & - & $2.43 \pm 0.25$ \\
& Diabetic & $-11.41 \pm 1.46(4)$ & $3.22 \pm 0.13$ & - & $9.21 \pm 1.52$ \\
& (7 days) & & & & \\
\hline
\end{tabular}

Colonocytes or enterocytes isolated from control or 7-day diabetic rats were incubated as described in the Materials and methods section in the presence of $5 \mathrm{mmol} / 1$-glutamine as a substrate. Rates are given as means $\pm \mathrm{SD}$, with the numbers of separate experiments given in parentheses. A negative sign indicates utilization. Significant differences from control rats are indicated by ${ }^{\mathrm{a}}(p<0.05){ }^{\text {b }}(p<0.01)$

Table 5. Arteriovenous-difference measurements for glutamine, glutamate, alanine and ammonia across the portal-drained viscera of control and streptozotocin-diabetic rats

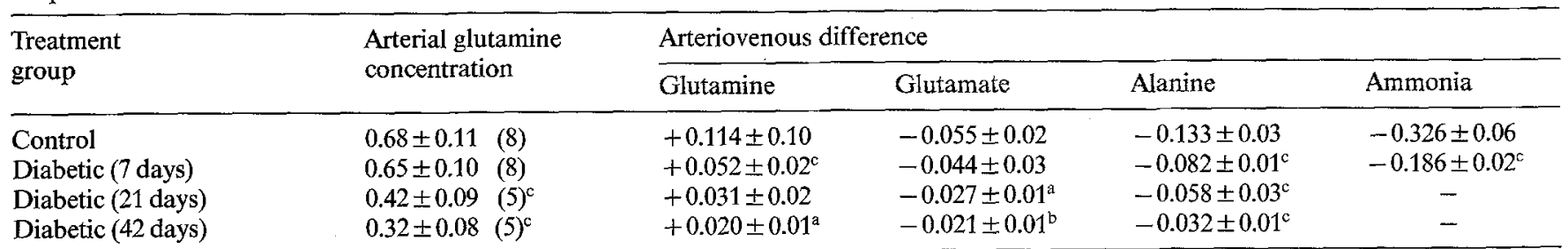

Measurements were made as described in the Materials and methods section; results are presented as means \pm SD with the numbers of animals given in parentheses. Values are expressed as $\mu \mathrm{mol}$ of metabolite $/ \mathrm{ml}$ of whole blood; negative values indicate release. Significant differences from control rats are indicated by ${ }^{\mathrm{a}}(p<0.05) ;{ }^{\mathrm{b}}(p<0.005),{ }^{\mathrm{c}}(p<0.001)$

\section{Glutamine metabolism by isolated colonocytes and enterocytes}

The rate of glutamine utilization by incubated rat colonocytes was $5.82 \mu \mathrm{mol} / \mathrm{min}$ per g (dry wt), whereas incubated rat enterocytes utilized glutamine at about twice this rate. The major end-products of glutamine metabolism are glutamate, aspartate and ammonia. Short-term diabetes caused a decrease in the rate of glutamine utilization by isolated colonocytes, which is accompanied by a diminished rate of formation of other nitrogenous end-products (Table 4). However, incubated enterocytes isolated from short-term diabetic rats showed no apparent differences in the rates of glutamine utilization or formation of glutamate, alanine and ammonia (Table 4).

\section{Arteriovenous-difference measurements for glutamine metabolism}

Arterial glutamine concentration was depressed by about $38 \%$ and $53 \%$ in 21 - and 42 -day diabetic rats, re- spectively, but showed no apparent change in shortterm diabetic animals (Table 5). Arteriovenous-difference measurements of glutamine and its major nitrogenous end-products (namely, glutamate, alanine and ammonia) across the gut of control, short- and longterm diabetic rats are presented in Table 5. Control rats exhibited a net glutamine removal from the circulation which was associated with the production of glutamate, alanine and ammonia. Net glutamine removal from the circulation was decreased by $54 \%, 73 \%$ and $85 \%$ in 7,21 and 42-day diabetic rats, respectively, which was accompanied by diminished rates of release of glutamate, alanine and ammonia (Table 5).

Arteriovenous-difference measurements across the kidney, liver and the hindlimb in short-term diabetic rats show a significant increase in the uptake of glutamine by both kidney and liver with a marked increase in the release of glutamine by skeletal muscle (Table 6).

Glutamine is released from skeletal muscle of fed or starved $[9,24-26]$ or diabetic rats $[7,27]$. In the present 
Table 6. Arteriovenous-difference measurements for glutamine across the gut, hindlimb, kidney and liver of short-or long-term diabetic rats

\begin{tabular}{lrrr}
\hline \multirow{2}{*}{ Tissue } & \multicolumn{3}{l}{ Arteriovenous difference $(\mathrm{nmol} / \mathrm{l})$} \\
\cline { 2 - 4 } & Control & $\begin{array}{l}\text { Diabetic } \\
(7 \text { days })\end{array}$ & $\begin{array}{l}\text { Diabetic } \\
\text { (42 days) }\end{array}$ \\
\hline Gut (8) & $+114.0 \pm 10.8$ & $+52.0 \pm 20.6^{\mathrm{a}}$ & $+19.8 \pm 10.2^{\mathrm{a}}$ \\
Hindlimb (5) & $-66.8 \pm 21.5$ & $-150.0 \pm 37.4^{\mathrm{b}}$ & $-172.2 \pm 39.8^{\mathrm{c}}$ \\
Kidney (5) & $+16.2 \pm 3.8$ & $+159.2 \pm 33.2^{\mathrm{c}}$ & $+197.6 \pm 54.8^{\mathrm{c}}$ \\
Liver (6) & $+27.5 \pm 13.4$ & $+69.2 \pm 28.3^{\mathrm{a}}$ & $+82.4 \pm 11.1^{\mathrm{c}}$ \\
\hline
\end{tabular}

Treatment and measurements were made as described in the Materials and methods section. Values are expressed as nmol/ 1 of glutamine of whole blood and presented as means $\pm S D$, with numbers of separate animals given in parentheses. Negative values indicate release. Significant differences from control rats are indicated by ${ }^{\mathrm{a}}(p<0.01)$; ${ }^{\mathrm{b}}(p<0.005){ }^{\mathrm{c}}(p<0.001)$

work, a significant increase in the release of glutamine was observed in diabetic rats $(p<0.001$, Table 6$)$ which is consistent with other reports $[9,27]$.

\section{Discussion}

Glutamine is known to be a major fuel for the mucosa of the small intestine $[11,28]$, and provides an important source of energy for colonocytes [6]. Using the whole of the small intestine, Watford et al. [8] showed a decrease (in acidosis), or an increase (in alkalosis and diabetes) in glutaminase activity. This has been confirmed in the present work, but the activity of the enzyme in the colon was decreased in short-term diabetes but unchanged in alkalosis or acidosis. The cause for this difference is not known, and it raises the question of why colonic glutaminase activity should behave differently to that of the small intestine. This could not have been due to the toxic side effect of streptozotocin, as the diminished colonic glutaminase activity in short-term diabetic rats was almost restored to normal value when diabetic rats were treated with insulin (Table 2). The increase in the activity of glutaminase of the small intestine, although it may suggest increased glutamine utilization by the small intestine, was not accompanied by enhanced rates of either glutamine removal in vivo or by isolated incubated intestinal mucosa of diabetic rats. However, in shortterm diabetes the capacity of the colonic mucosa to metabolize glutamine was decreased. This could be explained in part by the knowledge that colonic mucosa are less dependent on glutamine as a source of energy than the intestinal cells. This is supported by the finding that ketone-bodies and short-chain fatty acids contribute more to the fuels of respiration of colonocytes $[6$, 29].

The findings reported in other work [7-8] that glutamine utilization by the small intestine is suppressed in the diabetic rat has been confirmed in the present work in both short- and long-term diabetes, which was accompanied by a decreased capacity to utilize glutamine by the colon, but are inconsistent with reports of either little change in $[9,10]$ or complete cessation of [7] glutamine utilization by the small intestine in vivo during diabetes. This decrease in glutamine utilization by both the small intestine and the colon could be attributed to two factors: first, the sparing of glutamine for other tissues (e.g. kidney and liver) by alternative respiratory fuel(s). This could be related to the increased circulating concentrations of other metabolic fuels such as glucose, other amino acids and particularly ketone bodies. It is possible, therefore, that the diminished, but not total, suppression of glutamine utilization by the gut in diabetic rats is due to its partial replacement as a metabolic fuel by ketone bodies whose concentrations are greatly elevated $(>6 \mathrm{mmol} / \mathrm{l})$ in diabetic rats. This is consistent with the known absolute requirement of rapidly-dividing cells for glutamine [30-31]. Second, this decrease could be attributed to low arterial concentration of glutamine resulting in substrate unavailability due to increased utilization by other tissues such as kidney and liver. The latter has been confirmed in the present work (Table 6). Moreover, substrate unavailability could have been due to decreased release by skeletal muscle in response to diabetes. This was not seen in this study, as skeletal muscle continued to show enhanced release of glutamine in short- or long-term diabetes.

The ability of insulin to reverse the effects of streptozotocin-induced diabetes on the activity of intestinal and colonic glutaminase and the rapidity of the changes in the activity of the intestinal enzyme in response to acute changes in insulin concentration in vivo implicates insulin as one humoral factor, regulating directly or indirectly the intestinal and colonic glutaminase activities. The results of the present study suggest that whether insulin is involved in the regulation of intestinal glutaminase and therefore glutamine utilization, such regulatory action is apparently different from that in the colon. Although such a contention can only be proven by in vitro experimentation, it is consistent with recent reports that epithelial cells of the small intestine possess specific binding sites for insulin [32]. Therefore, it is concluded that insulin is involved in the regulation of glutaminase activity of both colonic and intestinal mucosa, but that it affects each differently. Further work is needed to explain this difference.

Acknowledgement. I gratefully acknowledge financial support from King Fahd Medical Research Center (KFMRC), College of Medicine and Allied Sciences, King Abdulaziz University, Jeddah, Kingdom of Saudi Arabia. I thank Mr. N. Golden for the measurements of plasma insulin.

\section{References}

1. Windmueller HG, Spaeth AE (1974) Uptake and metabolism of plasma glutamine by the small intestine. J Biol Chem 249: 5070-5079

2. Windmueller HG, Spaeth AR (1978) Identification of ketone bodies and glutamine as the major respiratory fuels in vivo for postabsorptive rat small intestine. J Biol Chem 253: 69-76 
3. Hanson PJ, Parsons DS (1977) Metabolism and transport of glutamine and glucose in vascularly perfused small intestine of rat. Biochem J 166: 509-519

4. Hanson PJ, Parsons DS (1978) Factors affecting the utilization of ketone bodies and other substrates by rat jejunum: effects of fasting and diabetes. J Physiol 278: 55-67

5. Watford M, Lund P, Krebs HA (1979) Isolation and metabolic characteristics of rat or chicken enterocytes. Biochem J 178: 589-596

6. Ardawi MSM, Newsholme EA (1985) Fuel utilization in colonocytes of the rat. Biochem $\mathrm{J} 231$ : 713-719

7. Brosnan JT, Man K-C, Hall DE, Colbourne SA, Brosnan ME (1983) Interorgan metabolism of amino acids in streptozotocindiabetic ketoacidotic rat. Am J Physiol 244: E151-E158

8. Watford M, Smith EM, Erbelding EJ (1984) The regulation of phosphate-activated glutaminase activity and glutamine metabolism in the streptozotocin-diabetic rat. Biochem J 224: 207-214

9. Schrock H, Goldstein L (1981) Interorgan relationships for glutamine metabolism in normal and acidotic rats. Am J Physiol 240: E519-E525

10. Felig P, Wahren J, Karl L, Cerasi E, Luft R, Kipnis DM (1973) Glutamine and glutamate metabolism in normal and diabetic subjects. Diabetes 22: 573-576

11. Kovacevic A, McGivan JD (1983) Mitochondrial metabolism of glutamine and glutamate and its physiological significance. Physiol Rev 63: 547-605

12. Budohoski L, Challis RAJ, Newsholme EA (1982) Effects of starvation on the maximal activities of some glycolytic and citric acidcycle enzymes and glutaminase in mucosa of the small intestine of the rat. Biochem J 206: 169-172

13. Ardawi MSM (1986) Pattern of fuel utilization in rat small intestinal mucosa after thermal injury. Digestive Dis Sci 31 (10): $417 \mathrm{~S}$

14. Neubauer HP, Schone HH (1978) The immunogenicity of different insulins in several animal species. Diabetes 27:8-15

15. Ardawi MSM, Newsholme EA (1983) Glutamine metabolism in lymphocytes of the rat. Biochem J 212: 835-842

16. Ardawi MSM, Newsholme EA (1982) Maximum activities of some enzymes of glycolysis, the tricarboxylic acid cycle and ketone-body and glutamine utilization pathways in lymphocytes of the rat. Biochem J 208: 743-748

17. Curthoys NP, Lowry OH (1973) The distribution of glutaminase isoenzymes in the various structures of the nephron in normal, acidotic and alkalotic rat kidney. J Biol Chem 248: 162-168

18. Slein MW (1963) Determination with Hexokinase and glucose6-phosphate dehydrogenase. In: Bergmeyer HU (ed) Methods of enzymatic analysis. Academic Press, New York, London, pp $117-123$

19. Bernt E, Bergmeyer HU (1974) UV-assay with glutamate dehydrogenase and NAD. In: Bergmeyer HU (ed) Methods of enzy- matic analysis, 2nd edn. Academic Press, New York, London, pp 1704-1708

20. Williamson DH, Lopex-Vieira O, Walker B (1967) Concentrations of free glucogenic amino acids in livers of rats subjected to various metabolic stresses. Biochem J 104: 497-502

21. Bergmeyer HU, Bernt E, Mollering H, Pfleiderer G (1974) L-Aspartate and L-asparagine. In: Bergmeyer HU (ed) Methods of enzymatic analysis, 2nd edn, Academic Press, New York, London, pp 1696-1700

22. Lowry OH, Rosebrough NJ, Farr AL, Randall RJ (1951) Protein measurement with the folin phenol reagent. J Biol Chem 193: 265-275

23. Pothier D, Hugon TS (1982) Immediate and localized response of intestinal mucosal enzyme activities in streptozotocin-diabetic mice. Comp Biochem Physiol 72 A: 505-513

24. Yamamoto $H$, Aikawa $T$, Matsutaka $H$, Okuda $T$, Ishikawa $E$ (1974) Interorganal relationships of amino acid metabolism in fed rats. Am J Physiol 226: 1428-1433

25. Ruderman NB (1975) Muscle amino acid metabolism and gluconeogenesis. Annu Rev Med 26: 245-258

26. Felig P (1975) Amino acid metabolism in man. Annu Rev Biochem 44: 933-955

27. MacDonald M, Neufeldt N, Park BN, Berger M, Ruderman N (1976) Alanine metabolism and gluconeogenesis in the rat. Am J Physiol 231: 619-625

28. Windmueller HG, Spaeth AE (1980) Respiratory fuels and nitrogen metabolism in vivo in small intestine of fed rats. J Biol Chem 255: 107-122

29. Roediger WEW (1982) Utilization of nutrients by isolated epithelial cells of the rat colon. Gastroenterology 83:424-429

30. Ardawi MSM, Newsholme EA (1985) Metabolism in lymphocytes and its importance in the immune response. Essays biochem 21: 1-44

31. McKeehan WL (1982) Glycolysis, glutaminolysis and cell proliferation. Cell Biol Int Rep 6: 635-647

32. Bergeron JJM, Sikstrom R, Hand AR, Posner BL (1979) Binding and uptake of ${ }^{125} \mathrm{I}$-insulin into rat liver hepatocytes and endothelium. J Cell Biol 80: 427-443

Received: 30 July 1986

and in revised form: 18 December 1986

Dr. M.S. M. Ardawi

Department of Clinical Biochemistry

College of Medicine and Allied Sciences

King Abdulaziz University

P.O. Box 9029

Jeddah 21413, Saudi Arabia 